\title{
Second School Education
}

\author{
Tânia Celeste Matos Nunes
}

Escola Politécnica de Saúde Joaquim Venâncio-Fiocruz, Av. Brasil 4036, 21049-361 Rio de Janeiro, RJ, Brasil

Key words: education - technical teaching - human resources

Having been asked to speak on Secondary School Education, I have taken as a reference two important areas of work of Escola Politécnica de Saúde Joaquim Venâncio of Oswaldo Cruz Foundation (Fiocruz): the area of scientific studies for Secondary School students through the Scientific Vocational Program in association with laboratories and other research institutes of Fiocruz and the training of professionals in the health area through technical graduation courses. I have decided to speak on the latter due to its importance in a scientific and technologic institution such as Fiocruz considering its contribution to laboratory work in the contemporary world and its relevance to discussions occurring now that the "Lei de Diretrizes e Bases" (the law that regulates education in Brazil) is being implemented in our country.

The training of technicians is an extremely important theme and is closely associated to the economic, social and political strategy of each country. The re-organization of the working process is also a very crucial issue to the formation of professionals in the area of teaching. It is important to take into consideration the importance of the technologic changes that have occurred in the health area in recent years. Traditional ways of teaching and learning have been redefined according to these changes. When it comes to the work market, in recent years there has been a great change in the type of positions being offered.

When it comes to laboratories, the technologic impact has been extremely demanding. There is great need for the training of technicians in this area.

It is worth saying that the implementation and reinforcement of the new "Lei de Diretrizes e Bases da Educação" has given way to a series of adjustments in the traditional teaching model.

Fax: +55-21-590.9122. E-mail: tcnunes@ fiocruz.br Received 7 August 2000

Accepted 4 September 2000
Whereas in the past a qualification was obtained only by the study of specific subjects, nowadays it is possible to obtain qualification by competence in some specific areas. This is what is already being done in countries such as France, England, Germany and Italy, among others.

The implementation of this law in Brazil, which will be done by December 2000, is a controversial issue. It has been opposed by intellectuals and researchers in the field of "work and education". Some authors criticize that the notion of competence may be linked to the rearrangement in the job market. Thus, they propose revising the concept of qualification which inspired the previous cycle and whose aim was preparing individuals to the job market, and suggest expanding this concept so as to be the basis of a new curriculum in the schools. As a result, this curriculum would go beyond the scientific knowledge.

There is a great number of books explaining the notion of competence and discussing how teachers should be prepared so that school programs may be more flexible considering the model that is to be adopted. To Manfredi, quoting Leite, the notion of competence is "used without discrimination, in the fields of education and work as if it had a universal connotation. Businessmen tend to define competence more as a capacity of acting, intervening, making decisions in situations that are not always foreseeable or predictable rather than having an ability to store knowledge. The performance at work and global productivity now depend very much on this capacity and on the ability to solve problems and make quick decisions".

Analyzing the demands for qualifications for jobs in the service sector, Deluiz develops a study that involves five groups of competence: basic and specific competence for a specific work group; organizational and methodological competence; communicative competence; competence in social skills and finally behavioral competence. Some authors organize these competences in three groups: the knowing how to do ( that involves practical, technical and scientific abilities acquired formally (through courses or training) and/or by professional experience; the knowing what to be, which includes traits of personality and character, such 
as capacity of initiative, communication, capacity to innovate and make changes, and the ability to adapt to new standards of quality and competitiveness; and last but not least the knowing how to act, which means being able to intervene and to make a decision when faced with challenges such as working in groups or doing a new type of work.

There has been a wide and rich debate on how to apply these new concepts in Brazil. This discussion will involve the need to redefine the idea of qualification. Thus, it will be also necessary to develop new and creative training programs for technicians. Such programs must then be based on these new concepts.

The new law regulating education in Brazil ("Lei de Diretrizes e Bases da Educação") will bring forth a new type of professional "the technologist", who will be trained in a course done after the Secondary School. How it will fit into the learning organization is an issue that is still being discussed. So far there have been some isolated initiatives in the health area; for instance: the Escola de Saúde Pública do Ceará recently started a course for "Technologists in Public Health". This may be an option for the laboratory area or for other areas related to health services. However, this definition involves aspects that need to be analyzed in depth, such as redefinition in the curriculum, the re-evaluation of the tendencies as to how groups are organized, especially in laboratories. There is a need of some deep investigation about the organization of work in the health area and also about how and if this model may be adopted by graduate schools in this field.

I feel it is important to say that it is a difficult time for those educators who are concerned about the reforms in our education system and in the teaching methodologies. This is a fertile field for the creation of alternative practices. So, I feel we must agree with Professor Lucilia Machado when she warns us that the qualification for the work force is being redefined. This new qualification involves several attributes, which are: basic education; the capacity to adapt to new situations; global understanding of some tasks and connected functions, which requires the ability to abstract and to select; handling and interpreting information; more attention and responsibility; a open attitude to learning and the creativity to face the unknown. Teamwork also demands the ability to communicate in a group.

To sum up, we want to stress that only through this debate and through the deep analysis of some model of training courses, we can advance towards a new model of training for technicians in the health sector. Some institutions have been experimenting with these new models. One example is the Escola Politécnica Joaquim Venâncio which implemented, in the 90s, the 4th Form Project in the graduation course for laboratory technicians and for the hospital administration technicians. This "project" made it possible to incorporate the element of research, leading to a better preparation of the students for the working life. The element of research is included in the course since the first year and is also part of the final assessment, when the student is about to graduate. This example represents an invaluable contribution to this debate and proves that the early preparation to research may well meet the expectations towards the training of the modern worker. This early preparation may also contribute to the shortening of the later cycles in the career of those who choose to work in the scientific field. Although these experiments are still being discussed, they will definitely help improving the training of health technicians in Brazil. 